Revista de Investigación Educativa 27

julio-diciembre, 2018 | ISSN 1870-5308 | Xalapa, Veracruz

Instituto de Investigaciones en Educación | Universidad Veracruzana

\title{
El impacto laboral de las competencias en el posgrado: el caso de los egresados de la Universidad Veracruzana en México
}

\author{
The labour impact of skills in graduate school: the case of \\ graduates of Universidad Veracruzana in Mexico
}

\author{
Teresita de Jesús Méndez Rebolledo ${ }^{\mathrm{a}}$ \\ Jordi Suriñach ${ }^{b}$ \\ Mario Miguel Ojeda Ramírez
}

Recibido: 17 de febrero de 2018

Aceptado: 10 de julio de 2018

Presentamos un análisis de las competencias genéricas que declaran los egresados del posgrado que tenían: (1) antes de iniciar sus estudios, (2) las que obtuvieron durante los estudios y (3) las que les requiere el desempeño laboral. Se realizan pruebas de hipótesis, se ajustan modelos de regresión lineal y modelo logístico multinomial. Se encontró que las competencias que más se adquieren y más se aplican están vinculadas con la profesionalización, habilidades del pensamiento analítico, de liderazgo y expositivas. Se concluye que existen semejanzas entre los niveles en los cuales los egresados logran las competencias con su aplicación en el ámbito en el que se desempeñan. Se demuestra que hay competencias de alta especialización obtenidas en el posgrado (habilidades comunicativas, de liderazgo e investigativas), lo que determina la pertinencia y significancia de un sistema de posgrados para darle soporte a la innovación en el desarrollo económico y social.

Palabras clave: Competencias genéricas; estudios de posgrado; egresados; trayectorias laborales; calidad.

\footnotetext{
a Doctoranda en Educación y Sociedad, Facultad de Educación, Universidad de Barcelona, España. ORCID: 0000-0002-8219-2020.凶 tmendere7@alumnes.ub.edu

b Doctor en Ciencias Económicas y Empresariales. Investigador, Universidad de Barcelona, España. ORCID: 0000-0003-2622-3280. 凶 jurinach@ub.edu

'Doctor en Ciencias Matemáticas. Académico, Facultad de Estadística e Informática, Universidad Veracruzana, México. ORCID: 0000-0001-6161-3968.凶 mojeda@uv.mx
} 
We present an analysis of those generic competences declared to have by graduates of graduate school: (1) before starting graduate school, (2) those obtained during graduate school and (3) those required by their work. We conduct statistical tests of hypothesis, and fit regression models, linear and logistic. We found that the competences that are most acquired and are the most applied are professionalization, skills of analytical thinking, leadership and oral communication. We conclude that there are similarities between the levels at which the graduates achieve the competences with their application in the field in which they work. We show that there are highly specialized competences obtained in graduated school (skills communication, leadership and research), which determine the relevance and significance of a graduate school system in order to support innovation in economic and social development.

Keywords: Generic skill; studies of postgraduate; graduates; work trajectories; quality.

\title{
El impacto laboral de las competencias en el posgrado: el caso de los egresados de la Universidad Veracruzana en México
}

\author{
The labour impact of skills in graduate school: the case of \\ graduates of Universidad Veracruzana in Mexico
}

\section{Introducción}

\begin{abstract}
A partir del siglo XX se han experimentado transformaciones económicas, 1 muchas de las cuales han sido impulsadas por fuerzas de procesos de innovación que caracterizan a la sociedad del conocimiento. En este contexto, se han propiciado cambios en la educación superior, explicados por la dinámica de las profesiones y el ejercicio laboral. El conocimiento y el acelerado desarrollo de las tecnologías de la información y la comunicación (TIC) han tenido injerencia en estos cambios.
\end{abstract}


Por lo mencionado en el párrafo anterior, las naciones se ven en la necesidad de invertir en formación de capital humano, investigación e innovación; mediante estrategias que eleven la producción científica y tecnológica. Sin embargo, es necesario considerar que la relación entre inversión en capital humano y el rendimiento económico es compleja, ya que las confrontaciones teóricas contra las evidencias empíricas han identificado que tales variables como clase social, género, edad, posesión de credenciales y títulos, también influyen en tal relación (Beneyto, 2013; Dore, 1976; Gilead, 2009; Villarreal, 2016).

Así, los esfuerzos por mejorar la educación y la formación deben complementarse con avances en el área de innovación, para lograr un incremento en la productividad laboral, generar empleos de calidad y reducir los niveles de informalidad en el trabajo (OCDE, 2015a). En México, de acuerdo con la OCDE (2015b), se tienen múltiples obstáculos para impulsar el potencial innovador del país. Algunos de estos obstáculos son una base interna de investigación deficiente, insuficiencia de recursos humanos con las competencias requeridas, y un entorno subdesarrollado que limita la apertura de empresas basadas en conocimiento (OCDE, 2015a, 2015b, 2017).

En los programas de posgrado — siendo ésta la cúspide de la educación superior y el espacio formativo que combina armónicamente la investigación y la vinculación, y promueve la innovación - es donde se expresa la amplia y creciente variedad de áreas del conocimiento. Estudiando este nivel educativo y sus políticas e impactos encontramos evidencias de la forma en que se van creando, recreando, fusionando e incluso desapareciendo las disciplinas científicas y profesionales (Rama, 2007). Son los estudios de posgrado en general, y el papel que desempeñan los egresados, en particular, una clara expresión de la sociedad del saber que se está expandiendo y que coloca al conocimiento como la fuente fundamental de la acumulación de capital. Así mismo, la rápida articulación de un sistema de posgrados diferenciados por niveles y categorías, similares a escala mundial, da cuenta de las interrelaciones globales. Podemos decir que la estructuración de diplomados, especializaciones, maestrías, doctorados y posdoctorados tiende a similares perfiles epistemológicos y de ámbitos laborales alrededor del orbe.

Retomando las consideraciones iniciales, se puede afirmar que la sociedad del conocimiento orienta a las Instituciones de Educación Superior (IES) al desarrollo de un sólido sistema de programas de posgrado, debido a que para los países significa mejorar la formación del capital humano. Por esta razón en México, a través del Consejo Nacional de Ciencia y Tecnología (CONACYT), se ha dado apoyo para 
el fortalecimiento del sistema científico y tecnológico, otorgando fondos crecientes en becas nacionales y al extranjero, para infraestructura y para proyectos de investigación e innovación.

Dentro de las principales acciones para el desarrollo de la ciencia en México está el apoyo para la creación y consolidación de programas educativos de posgrado en las IES públicas en cada estado. Con esto se busca articular el financiamiento para la investigación y la innovación con el diseño de los perfiles universitarios de egreso vinculados con el desarrollo de la ciencia, la cultura y los requerimientos sociales.

En este sentido, el conacyt y la Secretaría de Educación Superior de la Secretaría de Educación Pública (SEP) han impulsado, para el aseguramiento de la calidad de los programas educativos de posgrado, de 1991 a 2001, el Padrón de Excelencia; de 2002 a 2006, el Programa de Fortalecimiento al Posgrado Nacional (PFPN), y el Programa Nacional de Posgrados de Calidad (PNPC), el cual está vigente desde 2007.

En México se busca consolidar, a partir del PNPC, un sistema de formación del capital humano para enfrentar los retos de la sociedad del conocimiento. Es así que en los últimos veinte años se ha registrado un importante desarrollo del posgrado nacional, no sólo en términos cuantitativos (número de programas y matrícula de los estudiantes en maestría y doctorado), sino en la diversificación de campos de estudio, de ubicación regional y tipos de instituciones que albergan los programas (Grediaga, Rodríguez \& Padilla, 2004; Migdelina, 2015; Serna \& Pérez, 2012).

A pesar del impulso señalado, se asegura que existe la necesidad de fortalecer aún más el posgrado nacional. En los últimos años, el crecimiento acelerado de programas de posgrado de dudosa calidad en instituciones privadas — también de dudosa calidad - ha enviado una señal de alerta. Claramente se hace necesaria una mejora en la normativa para el desarrollo del posgrado mexicano, al grado que se requiere una actualización de la Ley de Educación. Así mismo, es necesario mejorar el presupuesto para emprender una verdadera política pública que contemple los recursos económicos necesarios para lograr, en un corto plazo, la consolidación de los estudios de posgrado en el país (Lozano, Gandini \& Ramírez, 2015; Serna, Cabrera, Pérez \& Salinas, 2013; Villa, 2012).

En este artículo se analizan, en un estudio de caso, los perfiles de competencias genéricas de egreso del posgrado vinculados con los que requiere el desempeño laboral, considerando todo tipo de estudiantes de posgrado (especialización, maestría y doctorado). El planteamiento de esta investigación surge a partir del requerimiento que realiza el PNPC, en el documento de Marco de Referencia para la Evaluación y 
Seguimiento de Programas de Posgrado, al solicitar a los programas educativos, el desarrollo del seguimiento de egresados, considerado como uno de los procedimientos que se asocia a los indicadores de calidad.

El objetivo de este artículo es analizar, para el curso de la Universidad Veracruzana (Uv), el nivel de competencias genéricas, divididas en la tipología utilizada como: técnicas, participativas, metodológicas, sociales y científicas de los egresados antes del posgrado y compararlo con el nivel adquirido y aplicado en el ámbito laboral. Así mismo, se quiere analizar si las competencias genéricas de egreso han sido de utilidad para mejorar variables clave del mercado de trabajo, como son el tipo de contratación, la actividad laboral, el régimen jurídico público y la remuneración económica. Las preguntas de investigación son:

- ¿En qué medida los egresados adquieren y aplican competencias genéricas?

- ¿Cómo se relacionan las características del trabajo con la tipología de las competencias genéricas adquiridas y aplicadas?

- ¿Cuánto se relacionan las características del trabajo con el perfil profesional, las características personales-laborales del egresado y las competencias genéricas? El trabajo se hizo con egresados de la uv, ubicada en el estado de Veracruz, en México. La oferta educativa de posgrado en este estado mexicano en 2012 fue de 578 programas, pertenecientes a 94 IES. De ellos, 402 corresponden a instituciones privadas y 176 a públicas, divididos en: 89 especializaciones, 442 maestrías y 47 doctorados. El número de programas de posgrado de la UV ese mismo año fue de 147, de los cuales 69 estaban reconocidos en el PNPC. Es claro que el posgrado de calidad en Veracruz tiene a la UV como la principal institución, puesto que concentra 9 de cada 10 de estos programas: 20 especializaciones, 19 especialidades médicas, 82 maestrías y 25 doctorados (Ojeda \& Castro, 2013).

\section{Antecedentes}

Las investigaciones que se citan a continuación son pioneras y algunas de ellas aún vigentes en el análisis de la relación de la formación universitaria con las características laborales de estudiantes y egresados. Tres proyectos que han logrado una visión integral del proceso de transición de los egresados al mundo laboral son: el proyecto Careers After Graduation An European Research Study (cheers) (Schomburg \& Teichler, 2006), el proyecto the Flexible Professional in Knowledge Society (REFLEX) 
(Dávila, Mora, Pérez \& Vila, 2015) y el proyecto del Profesional Flexible en la Sociedad del Conocimiento (Proflex) (Grisales, Carrión \& Mora, 2015; Mora, Carot \& Conchado, 2010). El primero, CHEERs, analizó la participación de egresados de Austria, Finlandia, Francia, Alemania, Italia, Países Bajos, España, Suecia, Reino Unido, Noruega, República Checa y Japón; exploró la relación de las competencias profesionales con las requeridas en el desempeño laboral. El segundo, REFLEX, contó con la participación de catorce países de Europa y Japón. Y el tercero, PROFLEX, cofinanciado por la Unión Europea y por universidades europeas y latinoamericanas, incluyó la participación también de estas últimas. De ellos se concluye que el enfoque de metodologías de enseñanza-aprendizaje constituye el fundamento tradicional de la práctica de formación (sustentada en la asistencia a clases); asimismo, el aprendizaje de teorías, conceptos y paradigmas constituye el sustento de los estudios universitarios según la percepción de los egresados, mientras que las metodologías de carácter interactivo, como la participación en proyectos o las prácticas en empresa, tienen menor aplicación en los procesos. En estos proyectos se identifica la situación laboral de los egresados universitarios, aunque no se aplica a egresados del posgrado.

También como parte del estado de la cuestión, sobre el vínculo de la formación y la inserción laboral, se encuentra el proyecto del Foro Universidad Empresa coordinado por la Universidad de Burgos, la Universidad de León, la Universidad de Salamanca y la Universidad de Valladolid. En el Foro Universidad Empresa analizan la empleabilidad de los titulados de Ciencias Sociales, Arte y Humanidades. Respecto al tema de competencias han concluido que potenciándolas pueden mejorar la empleabilidad del individuo. Y que las competencias más demandadas son actitudes en el trabajo, trabajo en equipo, responsabilidad y persistencia, resolución de problemas y conflictos, y planificación del propio trabajo (Carro, Lobato, Matas \& Corchado, 2018).

En Australia se encuentra el National Centre for Vocational Education Research (NCVER), que es una entidad que provee al gobierno, sector educativo, industrial y a la sociedad información sobre educación vocacional y entrenamiento. Ambos temas también vinculados con la formación y la inserción laboral. El NCVER se centra en encuestas para egresados y empleadores para conocer ingresos y la percepción de la educación impartida (McDonald, 2018).

En Francia, desde el Centro de Estudios e Investigaciones sobre Calificaciones (Cereq) se realizan estudios sobre el empleo, la evolución de las calificaciones y competencias. Los resultados de las investigaciones informan a las autoridades públicas, 
los agentes económicos y sociales acerca de cómo evolucionan las formaciones. También generan guías metodológicas para las IES y contribuye en el proceso de inserción de los egresados en el entorno laboral (Goffette \& Vero, 2016).

En Estados Unidos, el proyecto de la Secretary's Commission on Achiving Necessary Skills (2000) concluyó que de los egresados de pregrado más de la mitad culmina su formación sin los conocimientos básicos exigidos para conseguir un buen trabajo. Además, que las competencias transversales requeridas por el mercado laboral son las relativas a las relaciones interpersonales, que hacen referencia: al trabajo en equipo, la enseñanza de otros, el proporcionar servicio al cliente, ser líder, saber negociar y trabajar con diversas personas, entre las más referidas. Nuestro proyecto utiliza algunas de las competencias de la tipología que se usa este proyecto.

En general, después de esta revisión podemos decir que los estudios acerca de la inserción laboral de los egresados y las competencias que les requiere el mundo del empleo, se realizan desde cada una de las IEs. Además, estos estudios son regularmente de naturaleza exploratoria, evaluativa, con énfasis descriptivos, y en su inmensa mayoría centrados en el nivel de pregrado, aunque podemos encontrar algunos dedicados al nivel de posgrado, los cuales están regularmente asociados a programas, disciplinas o áreas de conocimiento. Podemos considerar que falta conocer más sobre el proceso formativo para los estudiantes y egresados de posgrado (Blömeke \& Kaiser, 2008; Chatenier, Verstegen, Biemans, Mulder \& Omta, 2010; Márquez, 1982; Méndez, 2018; Moreno, 2013; Ruiz \& Morfín, 2015; Sánchez, 2014).

En México, algunas instituciones han emprendido estudios de egresados del posgrado, algunos a nivel de programa o para áreas disciplinarias. En la UV se ha emprendido el diseño y desarrollo de un sistema de seguimiento de los egresados de su posgrado. Los primeros resultados descriptivos de este estudio se reportan en Ojeda, Figueroa, Bernal, y Castro (2014).

\subsection{Definición y tipología de competencias}

El concepto de competencia se utilizó primeramente por McClelland (1973). Sus trabajos identificaron a las competencias como una herramienta fundamental para asegurar la competitividad de las empresas. Afirmó que la contratación de una persona en la empresa implicaba ir más allá del certificado que portaba y de los resultados de test psicológicos; el mejor desempeño en el trabajo dijo que dependía de otras características de la persona, de sus competencias. Las competencias son indicado- 
res de la conducta o conductas observables, son variables que identifican el éxito en el desempeño laboral. Las competencias, en este sentido, son "las exigencias de una actividad profesional, comprendida como sistema de tareas básicas generalizadas y cualidades de las personas que se realizan y concretan en esta actividad o en sus productos" (Corral, 2004, p. 6). El modelo basado en competencias se ha convertido en una tendencia, pero todavía no hay suficientes líneas de orientación que ayuden a comprender prácticas más efectivas (Eizagirre, Altuna \& Fernández, 2017; Van \& Semeijn, 2004).

Una tipología de competencias la proponen Beneitone, Esquetini, González, Marty, Siufi y Wagenaar (2007). Distinguen entre genéricas, transversales y específicas. Las competencias genéricas son las que identifican elementos compartidos, comunes a cualquier titulación. Las competencias transversales son aquéllas cuya adquisición está distribuida en todo el currículo. Las competencias específicas son las que difieren de disciplina a disciplina.

En esta investigación se estudian las competencias genéricas, clasificadas en técnicas, metodológicas, sociales, participativas y científicas (Bunk, 1994; Ramírez \& Medina, 2008). Esta caracterización surge a partir del proyecto Tuning, que es un trabajo que identifica las competencias de profesionales en Europa y América Latina. También se basa en el proyecto del PROFLEX antes mencionado.

- Las competencias técnicas son:

1. Dominio de su área o disciplina (CARRERA_propia, CG1)

2. Conocimiento de otras áreas o disciplinas (OTRA_ÁREA, CG2)

3. Utilización de herramientas informáticas (USO_INFORMÁTICA, CG3)

4. Escribir y hablar en idiomas extranjeros (IDIOMA_EXTR, CG4)

- Las competencias metodológicas son:

5. Desarrollo del pensamiento analítico (PENSAM_ANALít, CG5)

6. Adquirir con rapidez nuevos conocimientos (ADQ_CONOCIM, CG6)

- Las competencias sociales son:

7. Negociar de forma eficaz (NEGOCIAR, CG7)

8. Capacidad para trabajar bajo presión (TRAB_BAJO_PRESIÓN, CG8)

9. Detectar nuevas oportunidades (DETECTAR_OPORT, CG9)

10. Coordinar actividades (COORD_ACT, CG1O)

11. Trabajar en equipo (TRAB_EQUIPO, CG11)

12. Talento para movilizar las capacidades de otros (MOVIL_CAPAC, CG12)

13. Hacerse comprender (HAC_COMPRENDER, CG13) 
- Las competencias participativas son:

14. Encontrar nuevas soluciones (NUEV_SOLUCIÓN, CG14)

15. Cuestionar ideas propias y ajenas (CUEST_IDEAS, CG15)

- Las competencias científicas son:

16. Presentar en público ideas, informes, ponencias y conferencias (PRES_EN_PÚBLICO, CG16)

17. Participary dirigir investigaciones (PARTIC_DIRIG_INVEST, CG17)

18. Redactar informes, documentos y publicarlos (REDAC_INFORMES, CG18)

\section{Metodología}

\subsection{Metodología de diseño}

Los datos que se utilizan son los del primer estudio de egresados del posgrado de la uv, recogidos por la Dirección General de la Unidad de Estudios de Posgrado, a partir de información proporcionada por los coordinadores de los programas educativos participantes, y por las coordinaciones regionales de posgrado. Se contó con el apoyo del Centro de Estudios de Opinión y Análisis de la misma uv.

La información considera a egresados de las generaciones de 1997 a 2013 de todos los campi de la Uv: Xalapa, Veracruz, Orizaba-Córdoba, Poza Rica-Tuxpan y Coatzacoalcos-Minatitlán. Se encuestaron egresados de 65 programas de posgrado: 7 de doctorado, 43 de maestría y 15 de especialización. El cuestionario estuvo conformado por 11 apartados que incluyen: el perfil del estudiante, información de contacto de los egresados, otras experiencias en el ámbito educativo, trayectoria laboral y datos laborales, competencias previas, adquiridas y aplicadas, orientación del posgrado, evaluación, comentarios y sugerencias al programa de posgrado. Se integró una base de datos de una población de 3,387 egresados, a quienes se les envió el cuestionario, de los cuales respondieron 410 los cuestionarios completos; también se obtuvieron 246 incompletos que no se analizan en este trabajo. La representatividad de la muestra se presenta en la Tabla 1. 
Tabla 1. La representatividad de la muestra

\begin{tabular}{|c|c|c|c|c|c|c|}
\hline \multirow{2}{*}{$\begin{array}{c}\text { Áreas de } \\
\text { conocimiento }\end{array}$} & \multirow{2}{*}{ Niveles } & \multirow{2}{*}{$\begin{array}{l}\text { Número de } \\
\text { Programas }\end{array}$} & \multicolumn{2}{|c|}{ Población } & \multicolumn{2}{|c|}{ Muestra } \\
\hline & & & $\mathbf{N}$ & $\%$ & $\mathbf{n}$ & $\%$ \\
\hline \multirow{3}{*}{ Técnica } & Especialización & 3 & \multirow{3}{*}{398} & \multirow{3}{*}{$11.75 \%$} & \multirow{3}{*}{56} & \multirow{3}{*}{$13.65 \%$} \\
\hline & Maestría & 5 & & & & \\
\hline & Doctorado & 0 & & & & \\
\hline \multirow{3}{*}{ Humanidades } & Especialización & 2 & \multirow{3}{*}{791} & \multirow{3}{*}{$23.35 \%$} & \multirow{3}{*}{71} & \multirow{3}{*}{$17.31 \%$} \\
\hline & Maestría & 7 & & & & \\
\hline & Doctorado & 2 & & & & \\
\hline \multirow{3}{*}{$\begin{array}{l}\text { Económico- } \\
\text { Administrativa }\end{array}$} & Especialización & 5 & \multirow{3}{*}{1019} & \multirow{3}{*}{$30.08 \%$} & \multirow{3}{*}{100} & \multirow{3}{*}{$24.39 \%$} \\
\hline & Maestría & 10 & & & & \\
\hline & Doctorado & 1 & & & & \\
\hline \multirow{3}{*}{ Ciencias de la Salud } & Especialización & 4 & \multirow{3}{*}{731} & \multirow{3}{*}{$21.58 \%$} & \multirow{3}{*}{113} & \multirow{3}{*}{$27.56 \%$} \\
\hline & Maestría & 10 & & & & \\
\hline & Doctorado & 1 & & & & \\
\hline \multirow{3}{*}{$\begin{array}{l}\text { Biológico- } \\
\text { Agropecuaria }\end{array}$} & Especialización & 1 & \multirow{3}{*}{406} & \multirow{3}{*}{$12.00 \%$} & \multirow{3}{*}{57} & \multirow{3}{*}{$13.92 \%$} \\
\hline & Maestría & 9 & & & & \\
\hline & Doctorado & 3 & & & & \\
\hline \multirow{3}{*}{ Artes } & Especialización & 0 & \multirow{3}{*}{42} & \multirow{3}{*}{$1.24 \%$} & \multirow{3}{*}{13} & \\
\hline & Maestría & 2 & & & & $3.17 \%$ \\
\hline & Doctorado & 0 & & & & \\
\hline & Especialización & 15 & & & & \\
\hline Total & Maestría & 43 & & & 110 & $100 \%$ \\
\hline Total & Doctorado & 7 & 3387 & $100 \%$ & 410 & $100 \%$ \\
\hline & Doctorado & 65 & & & & \\
\hline
\end{tabular}

Fuente: Elaboración propia.

Sobre la tipología de competencias genéricas, se pidió a los egresados que señalaran cómo valoraban su nivel de competencias antes del posgrado, qué nivel de competencias necesitaban en su trabajo y en qué medida había contribuido el posgrado del que egresaron al desarrollo de las competencias. La escala utilizada fue de $\mathrm{o}=\mathrm{Nada}$, $1=$ Muy bajo, $2=$ Bajo, $3=$ Medio, $4=$ Alto a $5=$ Muy alto. Los valores de las variables que se utilizan en el análisis de los datos son binarios, lo cual quiere decir 1 = presencia y $\mathrm{o}=$ ausencia de las características.

- Para el análisis de las características del trabajo se utilizan las variables: 
“actividad académica” (ACT_ACA)

"régimen jurídico público” (RÉG_JUR_PÚB)

"régimen jurídico privado" (RÉG_JUR_PRI)

"sector productivo primario" (SEC_PRO_PRI)

"sector productivo secundario" (SEC_PRO_SEC)

"sector productivo terciario" (SEC_PRO_TER)

"sectorproductivo:innovación, desarrolloeinvestigación"(SEC_PRO_I+D+i)

"tipo de contratación con base" (CON_BAS_SI)

"tipo de contratación sin base" (SIN_BAS_NO)

"remuneración económica más de 5 mil pesos mensuales" (REM_ECO_ MÁS_DE_CIN_MIL_PES_MEN)

"remuneración económica menos de 5 mil pesos mensuales" (REM_ECO_ MEN_DE_CIN_MIL_PES_MEN)

- Las variables que se utilizan en cuanto al perfil de egreso son:

“área de conocimiento técnica” (A_CON_TÉC)

"área de conocimiento humanidades" (A_CON_HUM)

"área de conocimiento económico-administrativa" (A_CON_ECO_ADMIN)

"área de conocimiento ciencias de la salud" (A_CON_C_SALUD)

"área de conocimiento biológico-agropecuaria" (A_CON_BIOL_AGROP)

“área de conocimiento artes" (A_CON_ARTES)

"nivel especialización” (ESP)

"nivel maestría" (MAE)

"nivel doctorado" (DOC)

"orientación del posgrado profesionalizante" (PRO)

"orientación del posgrado investigación" (INV)

- Las variables que conforman las características del egresado son:

"género masculino" (GÉN_MAS)

"género femenino" (GÉN_FEM)

“años laborales más de cinco" (AÑos_LAB_MÁs_DE_CINCO)

“años laborales menos de cinco" (AÑOS_LAB_MEN_DE_CINCO)

\subsection{Metodología de análisis}

En el apartado del cuestionario sobre ien qué medida los egresados adquieren y aplican competencias genéricas?, con el objetivo de analizar: (a) el nivel de competencias gené- 
ricas: técnicas, participativas, metodológicas, sociales y científicas de los egresados antes del posgrado, comparado con el nivel adquirido durante el mismo y aplicado al ámbito profesional; (b) en qué medida los egresados adquieren y aplican las competencias genéricas del posgrado, se cuantificaron las diferencias entre dominios de estudio y se aplicaron pruebas de t-student para evaluar la significancia estadística de estas diferencias.

Para los niveles iniciales y adquiridos de competencias se contrastaron las hipótesis $H_{o}: \mu=4$ contra las alternativas $H_{a}: \mu \neq 4$. Para el nivel aplicado de competencias se contrató la hipótesis $H_{o}: \mu=3$ contra la hipótesis alterna $H_{o}: \mu \neq 3$.

Posteriormente, se analiza la relación entre el grado de competencias genéricas (inicial, adquirido y aplicado) con el nivel de posgrado. Para este análisis se utilizaron modelos de regresión lineal, donde el nivel de posgrado (especialización, maestría y doctorado) es la variable explicatoria y la variable dependiente es cada una de las 18 competencias genéricas. Se ajustaron modelos por separado para cada uno de los niveles inicial, adquirido y aplicado. Esto permite analizar hasta qué punto el nivel del posgrado explica el nivel distinto de competencias genéricas (inicial, adquirido y aplicado) por sus egresados. Los modelo de regresión tiene la siguiente forma:

$$
y_{j i}=\beta_{1} E S P_{i}+\beta_{2} M A E_{i}+\beta_{3} D O C_{i}+\sum_{j=1}^{18} \gamma_{j} C G_{j i}+v_{i}
$$

donde la variable dependiente $y_{j i}$ es el valor de la competencia genérica (ya sea inicial, adquirida, aplicada) $j$ para el egresado $i, i=1, \ldots, n, j=1, \ldots, 18$. Las variables ESP, MAE y DOC son las indicadoras del nivel de posgrado (especialización, maestría y doctorado, respectivamente); y $C G_{j i}$ es la indicadora de la competencia genérica $j$ en el egresado $i$.

Sobre la pregunta de investigación ¿cuánto se relacionan las características del trabajo con la tipología de las competencias genéricas adquiridas y aplicadas?, se utilizó también regresión lineal. Las variables explicativas son las 18 competencias genéricas (de acuerdo con el nivel adquirido y aplicado) y las variables dependientes son "remuneración económica", "tipo de contratación”, "régimen jurídico" y "actividad académica”. Se ajustó un modelo de regresión de la siguiente forma para cada variable dependiente:

$$
z_{i}=\beta_{1} C G 1_{i}+\beta_{2} C G 2_{i}+\ldots+\beta_{18} C G 18_{i}+v_{i}
$$

donde $z_{i}$ es la característica del trabajo y $C G j_{i}$ es la competencia genérica adquirida $j$ por el egresado $i$. Este modelo permite estudiar la capacidad explicativa de las competencias genéricas (adquiridas y aplicadas) para con las características del mercado de trabajo (estas características medidas a través de la opinión de los egresados). 
Finalmente, sobre la pregunta de investigación: ¿cuánto se relacionan las características del trabajo con el perfil profesional, las características personales-laborales del egresado y las competencias genéricas?, se analizan las características del trabajo (con respecto al perfil de egreso), con las características personales-laborales del egresado y con las competencias genéricas. Para este análisis se usan modelos de regresión logística, donde las variables explicativas son las competencias genéricas, las características del trabajo, el perfil de egreso y características del egresado. La variable dependientes están determinadas por las variable dicotómicas tipo de contrato (si lo tiene $=1$, o no $=0$ ), remuneración económica (arriba de \$5,000 pesos mensuales $=1$, abajo $=0$ ), régimen jurídico del trabajo (privado $=$ o y público $=1$ ) y inserción laboral al sector académico $(s i ́=1$ o no $=0$ ). Se propone la especificación del siguiente modelo de regresión logística

$$
\begin{aligned}
& \operatorname{logit}\left(\pi_{i}\right)=\beta_{1} S E C \_P R O \_P R I_{i}+\beta_{2} S E C \_P R O \_S E C_{i}+\beta_{3} S E C \_P R O \_I+D+i_{i}
\end{aligned}
$$

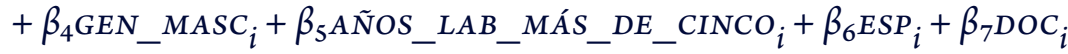

$$
\begin{aligned}
& +\beta_{8} I N V_{i}+\beta_{9} A \_C O N \_T E ́ C_{i}+\beta_{10} A \_C O N \_H U M_{i}
\end{aligned}
$$

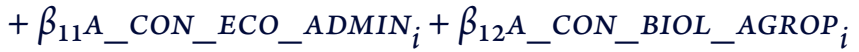

$$
\begin{aligned}
& +\beta_{13} A_{-} \text {CON_ARTES }{ }_{i}+\sum_{j=1}^{18} \gamma_{j} C G j_{i}
\end{aligned}
$$

donde $\pi_{i}$ es la probabilidad de que variable dependiente tome el valor 1 . La categoría base de las competencias genéricas es IDIOMA_EXTR, del género es GÉN_FEM, de los sectores productivos es SEC_PRO_TER, del nivel de posgrado es MAE, área de conocimiento es A_CON_C_SALUD, de la orientación de posgrado es PRO, y de los años laborales es AÑOS_LAB_MENOS_DE_CINCO.

\section{Resultados}

\section{1 ¿En qué medida los egresados adquieren y aplican competencias genéricas?}

Los egresados respondieron preguntas sobre el nivel inicial (antes de cursar el posgrado), el nivel adquirido de las competencias genéricas, así como el nivel de competencias genéricas que aplicaban en su trabajo después de cursar el posgrado. El rango de respuesta iba del $\mathrm{o}=\mathrm{Nada}, 1=$ Muy bajo, $2=$ Bajo, $3=$ Medio, $4=$ Alto al $5=$ Muy alto. 


\subsubsection{El nivel inicial de competencias genéricas}

Los resultados muestran que para el nivel inicial todos los egresados, en todas las competencias genéricas, llegan con un nivel de competencias genéricas mayor de 3 (valor medio) antes de cursar el posgrado, y para 7 competencias genéricas, mayor de 4; como se ve en la Tabla 2.

Tabla 2. El nivel inicial de competencias genéricas

\begin{tabular}{lcccc}
\hline \multirow{2}{*}{ Competencia } & N & Error. Típ. & t4 & Sig. t4 \\
\cline { 2 - 5 } & 332 &, 032 & 6,722 & $<.001$ \\
\hline CARRERA_PROPIA & 332 &, 038 & $-6,975$ & $<.001$ \\
\hline OTRA_ÁREA & 333 &, 032 & 9,584 & $<.001$ \\
\hline USO_INFORMÁTICA & 331 &, 037 & 6,833 & $<.001$ \\
\hline IDIOMA_EXTR & 364 &, 042 & $-7,675$ & $<.001$ \\
\hline PENSAM_ANALÍT & 364 &, 040 & 1,160 &, 247 \\
\hline ADQ_CONOCIM & 364 &, 048 & 2,245 &, 025 \\
\hline NEGOCIAR & 364 &, 048 & $-1,841$ &, 066 \\
\hline TRAB_BAJO_PRESIÓN & 364 &, 050 & $-3,805$ & $<.001$ \\
\hline DETECTAR_OPORT & 364 &, 052 & $-6,198$ & $<.001$ \\
\hline COORD_ACTIV & 364 &, 043 & 1,709 &, 088 \\
\hline TRAB_EQUIPO & 364 &, 048 &, 625 &, 532 \\
\hline MOVIL_CAPAC & 364 &, 055 & $-3,652$ & $<.001$ \\
\hline HAC_COMPRENDER & 324 &, 037 & 7,820 & $<.001$ \\
\hline NUEV_SOLUCIÓN & 324 &, 039 & 5,648 & $<.001$ \\
\hline CUEST_IDEAS & 324 &, 049 & 2,671 &, 008 \\
\hline PRES_EN_PÚBLICO & 326 &, 051 & $-3,587$ & $<.001$ \\
\hline PARTIC_DIRIG_INVEST & 325 &, 055 & $-2,631$ &, 009 \\
\hline REDAC_INFORMES & & & ,001 \\
\hline
\end{tabular}

$\mathrm{N}$ : número de observaciones. Error típico: estimación de la desviación típica del valor medio de la variable. $\mathrm{t} 4$ : $\mathrm{t}$-student con un valor de prueba de 4. Sig. t4: nivel de significación con un valor de prueba de 4.

Fuente: Elaboración propia. 


\subsubsection{El nivel adquirido de competencias genéricas}

Se encontró que todos los egresados sí adquieren un nivel de competencias genéricas superior a 3, excepto en la competencia de Redactar informes, documentos y publicarlos; y en 7 competencias genéricas (Dominio de su área o disciplina, Escribir y hablar en idiomas extranjeros, Desarrollo del pensamiento analítico, Negociar de forma eficaz, Coordinar actividades, Cuestionar ideas propias y ajenas y Presentar en público ideas, informes, ponencias y conferencias) el nivel adquirido es igual a 4, luego de cursar el programa de posgrado (Tabla 3 ).

\section{Tabla 3. El nivel adquirido y aplicado de competencias genéricas}

\begin{tabular}{|c|c|c|c|c|c|c|c|c|c|c|c|c|}
\hline \multirow[b]{2}{*}{ Competencia } & \multicolumn{6}{|c|}{ Nivel adquirido } & \multicolumn{6}{|c|}{ Nivel aplicado } \\
\hline & $\mathbf{N}$ & $\begin{array}{c}\text { Error } \\
\text { Típ. }\end{array}$ & t3 & Sig. $t_{3}$ & t4 & Sig.t4 & $\mathbf{N}$ & $\begin{array}{c}\text { Error } \\
\text { Típ. }\end{array}$ & t3 & Sig. $t_{3}$ & t4 & Sig. $t_{4}$ \\
\hline CARRERA_PROPIA & 328 & ,047 & 22,723 & $<.001$ & 1,428 & 154 & 363 & ,043 & 24,092 & $<.001$ & 771 & ,441 \\
\hline OTRA_ÁREA & 334 &, 055 & 16,254 & $<.001$ & $-2,025$ &, 044 & 363 &, 042 & 15,929 & $<.001$ & $-7,769$ & $<.001$ \\
\hline USO_INFORMÁTICA & 327 &, 049 & 13,057 & $<.001$ & $-7,372$ & $<.001$ & 363 &, 037 & 30,096 & $<.001$ & 3,385 & ,001 \\
\hline IDIOMA_EXTR & 332 &, 050 & 20,566 & $<.001$ & 601 &, 548 & 363 &, 040 & 25,915 & $<.001$ & 1,094 & 275 \\
\hline PENSAM_ANALÍT & 334 &, 052 & 18,175 & $<.001$ & $-1,219$ & 224 & 363 &, 050 & 12,015 & $<.001$ & $-8,084$ & $<.001$ \\
\hline ADQ_CONOCIM & 332 & ,057 & 9,385 & $<.001$ & $-8,218$ & $<.001$ & 363 & ,048 & 23,119 & $<.001$ & 2,191 &, 029 \\
\hline NEGOCIAR & 338 & ,059 & 15,912 & $<.001$ & $-1,054$ & 293 & 363 & ,048 & 17,796 & $<.001$ & $-2,976$ & ,003 \\
\hline TRAB_BAJO_PRESIÓN & 336 & ,058 & 12,551 & $<.001$ & $-4,732$ & $<.001$ & 363 &, 048 & 19,026 & $<.001$ & $-1,903$ & ,058 \\
\hline DETECTAR_OPORT & 328 & ,054 & 15,803 & $<.001$ & $-2,709$ &, 007 & 363 & ,044 & 25,898 & $<.001$ & 3,080 & ,002 \\
\hline COORD_ACTIV & 332 &, 053 & 19,164 & $<.001$ & 451 &, 652 & 363 &, 050 & 16,193 & $<.001$ & $-3,869$ & $<.001$ \\
\hline TRAB_EQUIPO & 335 &, 059 & 11,598 & $<.001$ & $-5,295$ & $<.001$ & 363 &, 044 & 22,800 & $<.001$ & ,187 & 852 \\
\hline MOVIL_CAPAC & 340 &, 055 & 16,168 & $<.001$ & $-2,156$ &, 032 & 363 & ,052 & 13,093 & $<.001$ & $-6,149$ & $<.001$ \\
\hline HAC_COMPRENDER & 334 & ,059 & 10,188 & $<.001$ & $-6,742$ & $<.001$ & 363 & 051 & 17,407 & $<.001$ & $-2,278$ & , 023 \\
\hline NUEV_SOLUCIÓN & 326 &, 062 & 12,846 & $<.001$ & $-3,323$ & , 001 & 363 & ,043 & 24,661 & $<.001$ & 1,648 &, 100 \\
\hline CUEST_IDEAS & 321 &, 053 & 18,692 & $<.001$ &, 000 & 1,000 & 363 &, 045 & 23,368 & $<.001$ & 1,104 &, 270 \\
\hline PRES_EN_PÚBLICO & 319 &, 052 & 19,633 & $<.001$ & 422 & ,674 & 363 & ,048 & 21,258 & $<.001$ &, 625 &, 532 \\
\hline PARTIC_DIRIG_INVEST & 343 &, 062 & 13,304 & $<.001$ & $-2,935$ &, 004 & 363 &, 059 & $-1,578$ &, 115 & $-18,428$ & $<.001$ \\
\hline REDAC_INFORMES & 343 & ,062 & $-2,397$ &, 017 & $-18,517$ & $<.001$ & 409 & ,061 & $-7,070$ & $<.001$ & $-23,498$ & $<.001$ \\
\hline
\end{tabular}

$\mathrm{N}$ : número de observaciones. Error típico: estimación de la desviación típica del valor medio de la variable. $t_{3}$ : t-student con un valor de prueba de la media poblacional de 3. Sig. t3: nivel de significación con un valor de prueba de la media poblacional de $3 . \mathrm{t}_{4}$ : $\mathrm{t}$-student con un valor de prueba de la media poblacional de 4. Sig. t4: nivel de significación con un valor de prueba de la media poblacional de 4 .

Fuente: Elaboración propia. 


\subsubsection{El nivel aplicado de competencias genéricas}

Se encontró que todos los egresados sí aplican en su trabajo un nivel de competencias genéricas igual o superior a 3, excepto en Redactar informes, documentos y publicarlos; y en 7 competencias genéricas (Dominio de su área o disciplina, Escribir y hablar en idiomas extranjeros, Capacidad para trabajar bajo presión, Trabajar en equipo, Encontrar nuevas soluciones, Cuestionar ideas propias y ajenas y Presentar en público ideas, informes, ponencias y conferencias) el nivel aplicado es igual a 4 y en 3 mayor a 4 (Utilización de herramientas informáticas, Adquirir con rapidez nuevos conocimientos y Detectar nuevas oportunidades) (Tabla 3 ).

\subsection{Las competencias genéricas desde el nivel de posgrado}

En las diferencias en cuanto al nivel de competencias genéricas inicial, aplicado y adquirido, según la tipología de posgrado, se demuestra que existen diferencias significativas entre los niveles de las competencias genéricas en los niveles de posgrado, es decir, entre egresados de especialización, maestría y doctorado. Así, los egresados de maestría tienen un efecto diferencial superior de competencias genéricas (inicial, adquirida o aplicada), respecto a los egresados de especialización; y los egresados del nivel de doctorado también tienen un efecto diferencial superior de competencias genéricas, en comparación a los estudiantes de especialización. Este efecto diferencial se produce tanto en el nivel inicial, como en el aplicado y adquirido (Tabla 4 ).

Tabla 4. Las competencias genéricas desde el nivel de posgrado

\begin{tabular}{lcccccc}
\hline \multirow{2}{*}{ Nivel de posgrado } & \multicolumn{7}{c}{ Competencias } \\
\cline { 2 - 7 } & \multicolumn{2}{c}{ Inicial } & \multicolumn{2}{c}{ Aplicado } & \multicolumn{2}{c}{ Adquirido } \\
\cline { 2 - 7 } & B & Sig. & B & Sig. & B & Sig. \\
\hline Constante & 3,658 & $<.001^{* * *}$ & 3,930 & $<.001^{* * *}$ & 3,668 & $<.001^{* * *}$ \\
\hline Maestría $^{1}$ &, 171 & $<.001^{* * *}$ &, 232 & $<.001^{* * *}$ &, 167 & $<.001^{* * *}$ \\
\hline Doctorado $^{1}$ &, 221 & $<.001^{* * *}$ &, 202 & $<.001^{* * *}$ &, 255 & $<.001^{* * *}$ \\
\hline Dominio de competenciass $^{2}$ & Sí & Sí & Sí & Sí & Sí & Sí \\
\hline
\end{tabular}

${ }^{1}$ La categoría de referencia es el nivel de posgrado de especialización.

${ }^{2}$ Dominio de competencias (CG) incluye variables ficticias que representan la pertinencia a cada nivel de posgrado.

$$
\text { ***: } 1 \% \text {. }
$$

Fuente: Elaboración propia. 


\section{3 ¿Cuánto se relacionan las características del trabajo con la tipología de las competencias genéricas adquiridas y aplicadas?}

En relación con el objetivo de analizar la contribución de las competencias genéricas para explicar las variables clave del mercado de trabajo, los resultados muestran que los modelos globalmente son significativos, al 10\% de significación para el "régimen jurídico" $\left(0,069^{*}\right)$, en las competencias genéricas aplicadas; y en la inserción a la "actividad académica” $\left(0,032^{* *}\right)(\mathrm{al} 5 \%)$, en las competencias genéricas adquiridas. En la Tabla 5 se resume la significación global de cada modelo.

\section{Tabla 5. La relación del nivel adquirido y aplicado de competencias genéricas con las características del trabajo}

\begin{tabular}{|c|c|c|c|c|c|c|c|c|}
\hline \multirow{3}{*}{$\begin{array}{c}\text { Nivel de } \\
\text { competencias } \\
\text { genéricas }\end{array}$} & \multicolumn{8}{|c|}{ Características del trabajo } \\
\hline & \multicolumn{2}{|c|}{ 1. Remuneración } & \multicolumn{2}{|c|}{$\begin{array}{l}\text { 2. Tipo de } \\
\text { contratación }\end{array}$} & \multicolumn{2}{|c|}{$\begin{array}{l}\text { 3. Régimen } \\
\text { jurídico }\end{array}$} & \multicolumn{2}{|c|}{$\begin{array}{l}\text { 4. Actividad } \\
\text { académica }\end{array}$} \\
\hline & $\mathbf{F}$ & Sig. & $\mathbf{F}$ & Sig. & $\mathbf{F}$ & Sig. & $\mathbf{F}$ & Sig. \\
\hline Aplicado & 1,256 & ,215 &, 798 &, 703 & 1,562 & $069^{*}$ & 940 &, 530 \\
\hline Adquirido &, 388 & 987 & 679 & 823 & 750 &, 750 & 1,768 &, $032^{* *}$ \\
\hline
\end{tabular}

De todos modos, y para analizar con más detalle cómo se relacionan las características del trabajo con la tipología de las competencias genéricas adquiridas y aplicadas, a partir de la Tabla 6 se concluye que, aunque los modelos globales no todos son significativos, sí lo son determinadas competencias genéricas aplicadas y adquiridas durante el posgrado. Por un lado se encontró que la única competencia adquirida que es significativa para estar inserta en la actividad laboral académica es la competencia Redactar informes, documentos y publicarlos $\left(<0,001^{* * *}\right)$. En cuanto a las competencias genéricas aplicadas, en la Tabla 7 se presentan las que son significativas al 1\%, 5\% o 10\% de nivel de significación. Como puede observarse, algunas competencias genéricas aplicadas son significativas al 1\% y 5\% (básicamente para explicar el nivel de remuneración alcanzado por el egresado). La aplicación de la 
competencia Hacerse comprender $\left(0,094^{*}\right)\left(0,012^{* *}\right)\left(0,060^{*}\right)$ es la que aparece significativa en tres de los cuatro modelos.

\section{Tabla 6. Las competencias genéricas que mejoran las características del trabajo}

\begin{tabular}{|c|c|c|c|c|c|c|c|c|}
\hline \multirow{3}{*}{$\begin{array}{c}\text { Nivel de } \\
\text { competencias } \\
\text { genéricas }\end{array}$} & \multicolumn{8}{|c|}{ Características del trabajo } \\
\hline & \multicolumn{2}{|c|}{ 1. Remuneración } & \multicolumn{2}{|c|}{ 2. Tipo de contratación } & \multicolumn{2}{|c|}{ 3. Régimen jurídico } & \multicolumn{2}{|c|}{ 4. Actividad académica } \\
\hline & $\begin{array}{c}\text { Competencias } \\
\text { genéricas }\end{array}$ & Sig. & $\begin{array}{c}\text { Competencias } \\
\text { genéricas }\end{array}$ & Sig. & $\begin{array}{l}\text { Competencias } \\
\text { genéricas }\end{array}$ & Sig. & $\begin{array}{c}\text { Competencias } \\
\text { genéricas }\end{array}$ & Sig. \\
\hline \multirow{4}{*}{ Aplicado } & MOVIL_CAPAC &, $045^{* *}$ & \multirow{2}{*}{$\begin{array}{c}\text { CARRERA_- } \\
\text { PROPIA }\end{array}$} & \multirow[b]{2}{*}{, $069^{*}$} & OTRA_ÁREA &, $059^{*}$ & \multirow{2}{*}{$\begin{array}{c}\mathrm{HAC}_{-} \\
\text {COMPRENDER }\end{array}$} & \multirow[b]{2}{*}{, $060^{*}$} \\
\hline & $\begin{array}{c}\mathrm{HAC}_{-} \\
\text {COMPRENDER }\end{array}$ &, $094^{*}$ & & & \multirow{2}{*}{ MOVIL_CAPAC } & \multirow{2}{*}{, $008^{* * *}$} & & \\
\hline & $\begin{array}{l}\text { PRES_EN_- } \\
\text { PÚBLICO }\end{array}$ &, $025^{* *}$ & \multirow{2}{*}{$\begin{array}{c}\text { HAC_ } \\
\text { COMPRENDER }\end{array}$} & \multirow{2}{*}{, $012^{* *}$} & & & \multirow{2}{*}{$\begin{array}{l}\text { NUEV_- } \\
\text { SOLUCIÓN }\end{array}$} & \multirow{2}{*}{, $078^{*}$} \\
\hline & $\begin{array}{c}\text { PARTIC_DIRIG_ } \\
\text { INVEST }\end{array}$ &, $031^{* *}$ & & & CUEST_IDEAS &, $095^{*}$ & & \\
\hline Adquirido & & & & & & & $\begin{array}{l}\text { REDAC_ } \\
\text { INFORMES }\end{array}$ & $<.001^{* * * *}$ \\
\hline
\end{tabular}

Los modelos globalmente significativos se encuentran indicados con uno, dos o tres asteriscos, con $\left({ }^{*}\right)$ al 10\%, $\left({ }^{* *}\right)$ al $5 \%$ y $\left(^{* * *}\right)$ al $1 \%$.

Fuente: Elaboración propia.

\section{4 ¿Cuánto se relacionan las características del trabajo con el perfil profesional, las características personales- laborales del egresado y las competencias genéricas?}

A partir de los odd ratio de cada uno de los resúmenes del modelo "régimen jurídico", "remuneración económica", "tipo de contratación" y "actividad académica" se realiza la Tabla 7, identificando únicamente las variables que resultan significativas para cada modelo. 
Teresita de Jesús Méndez Rebolledo, Jordi Suriñach, Mario Miguel Ojeda Ramírez

\section{Tabla 7. Resumen de los modelos de las características del trabajo}

\begin{tabular}{|c|c|c|c|c|}
\hline \multirow{2}{*}{$\begin{array}{l}\text { Competencias } \\
\text { genéricas }\end{array}$} & \multicolumn{4}{|c|}{ Características del trabajo } \\
\hline & Régimen jurídico & Remuneración económica & Tipo de contratación & Actividad académica \\
\hline \multirow{7}{*}{ Adquiridas } & $\begin{array}{l}\text { 1. TRAB_EQUIPO }(71.7 \%)^{*} \\
\text { 2.PRES_EN_PÚBLICO } \\
(-39.7 \%)^{*}\end{array}$ & & 1. COORD_ACTIV $(51.2 \%)^{*}$ & $\begin{array}{l}\text { 1. TRAB_EQUIPO }(76.1)^{* * *} \\
\text { 2. REDAC_INFORMES } \\
(-36.1)^{* * *}\end{array}$ \\
\hline & $\begin{array}{l}\text { 3. SECT_PROD_PRIM } \\
(328.4 \%)^{* *} \\
\text { 4. SECT_PROD_SECUN } \\
(329.5 \%)^{* * *}\end{array}$ & & & $\begin{array}{l}\text { 3.SECT_PROD_PRIM } \\
(503.6 \%)^{* *} \\
\text { 4. SECT_PROD_SECUN } \\
(458.8 \%)^{* *}\end{array}$ \\
\hline & $\begin{array}{l}\text { 5. N_P_ESPEC }(260.9 \%)^{* * *} \\
\text { 6. N_P DOCTOR }(-77.1 \%)^{*}\end{array}$ & & $\begin{array}{l}\text { 2. N_P_DOCTOR } \\
(-61.5 \%)^{* *}\end{array}$ & $\begin{array}{l}\text { 5. N_P_ESPEC }(120.9 \%)^{*} \\
\text { 6.N_P_DOCTOR }(-56.6 \%)^{*}\end{array}$ \\
\hline & & & 3. A_CON_TÉC $(-62.7 \%)^{* *}$ & \\
\hline & & & $\begin{array}{l}\text { 4. 0_P_INVEST } \\
(142.8 \%)^{* *}\end{array}$ & \\
\hline & $\begin{array}{l}\text { 7. AÑOS_LAB_MÁS_DE_ } \\
\text { CINCO }(-59.4 \%)^{* * * *}\end{array}$ & & $\begin{array}{l}\text { 5. AÑOS_LAB_MÁS_DE_ } \\
\text { CINCO }(-60.8 \%)^{* * *}\end{array}$ & $\begin{array}{l}\text { 6. AÑOS_LAB_MÁS_DE_ } \\
\text { CINCO }(-45.5 \%)^{* *}\end{array}$ \\
\hline & & 1. GÉN_MASC (168.6\%) ${ }^{* *}$ & & \\
\hline \multirow{7}{*}{ Aplicadas } & $\begin{array}{l}\text { 1. OTRA_ÁREA }(75.2 \%)^{* *} \\
\text { 2. TRAB_EQUIPO }(87.6 \%)^{*} \\
\text { 3. MOVIL_CAPAC }(-48 \%)^{* * *}\end{array}$ & $\begin{array}{l}\text { 2. ADQ_CONOCIM }(90 \%)^{*} \\
\text { 3. HAC_COMPRENDER }(-44.1 \%)^{*} \\
\text { 4. NUEV_SOLUCIÓN }(78.9 \%)^{*} \\
\text { 5. PARTIC_DIRIG_INVEST }(-58.4 \%)^{* *} \\
\text { 6. REDAC_INFORMES }(-42.8)^{* *}\end{array}$ & $\begin{array}{l}\text { 6. CARRERA_PROPIA } \\
(48 \%)^{*} \\
\text { 7. COORD_ACTIV }(56.1 \%)^{*} \\
\text { 8. NUEV_SOLUCIÓN } \\
(-35.5)^{*}\end{array}$ & $\begin{array}{l}\text { 1. NUEV_SOLUCIÓN } \\
(69.8 \%)^{* *}\end{array}$ \\
\hline & 4. GÉN_MASC (101.2\%)* & & & \\
\hline & $\begin{array}{l}\text { 5.SECT_PROD_PRIM } \\
(437.6 \%)^{* *} \\
\text { 6.SECT_PROD_SECUN } \\
(333.1 \%)^{* * *}\end{array}$ & 7.SECT_PROD_I+D+i $(143,9 \%)^{*}$ & $\begin{array}{l}\text { 9. SECT_PROD_PRIM } \\
(494 \%)^{* *}\end{array}$ & $\begin{array}{l}\text { 2. SECT_PROD_PRIM } \\
(607.7 \%)^{* *} \\
\text { 3. SECT_PROD_SECUN } \\
(420 \%)^{* *} \\
\text { 4. SECT_PROD_I+D+i } \\
(106.6 \%)^{*}\end{array}$ \\
\hline & $\begin{array}{l}\text { 7. N_P_ESPEC }(338.3 \%)^{* * *} \\
\text { 8. N_P_DOCTOR }(-84.2 \%)^{* *}\end{array}$ & & $\begin{array}{l}\text { 10. N_P_DOCTOR } \\
(-59.3 \%)^{*}\end{array}$ & $\begin{array}{c}\text { 4. N_P_ESPEC } \\
(254.4 \%)^{* * *} \\
\text { 5. N_P_DOCTOR } \\
(-70.8 \%)^{* * *}\end{array}$ \\
\hline & 9. A_CON_ARTES $(-90.9 \%)^{*}$ & & & \\
\hline & & & $\begin{array}{l}\text { 11. 0_P_INVEST } \\
(180.8 \%)^{* * * *}\end{array}$ & \\
\hline & $\begin{array}{l}\text { 10. AÑOS_LAB_MÁS_DE } \\
\text { CINCO }(-69.6 \%)^{* * *}\end{array}$ & & $\begin{array}{l}\text { 12. AÑOS_LAB_MÁS_ } \\
\text { DE_CINCO }(-56.8 \%)^{* * *}\end{array}$ & $\begin{array}{l}\text { 6. AÑOS_LAB_MÁS_DE_- } \\
\text { (INCO }(-41.5 \%)^{*}\end{array}$ \\
\hline
\end{tabular}

Los modelos globalmente significativos, se encuentran indicados con uno, dos o tres asteriscos, con $\left(^{*}\right)$ al $10 \%,\left({ }^{* *}\right)$ al $5 \%$ y $\left({ }^{* *}\right)$ al $1 \%$.

Fuente: Elaboración propia. 
Conforme a los modelos que incorporan las competencias genéricas adquiridas, sólo las competencias Trabajar en equipo y Presentar en público ideas, informes, ponencias $y$ conferencias muestran un efecto diferencial respecto a la categoría base Escribir $y$ hablar en idiomas extranjeros (para estar inserto en el "régimen jurídico público"). Así mismo, la competencia adquirida Coordinar actividades es la única que presenta un efecto diferencial sobre la categoría base Escribir y hablar en idiomas extranjeros (para tener un tipo de "contratación de base"). Las competencias genéricas adquiridas Trabajar en equipo y Redactar informes, documentos y publicarlos presentan un efecto diferencial respecto a la categoría base Escribir y hablar en idiomas extranjeros (para insertarse en la "actividad académica”).

Tales competencias genéricas adquiridas corresponden a las habilidades de liderazgo, habilidades vinculadas con la actividad académica y científica.

Las competencias genéricas aplicadas Conocimiento de otras áreas o disciplinas, Trabajar en equipo y Talento para movilizar las capacidades de otros presentan un efecto diferencial respecto a la categoría base Escribir y hablar en idiomas extranjeros (para estar inserto en el "régimen jurídico público").

Las competencias genéricas aplicadas Adquirir con rapidez nuevos conocimientos y Encontrar nuevas soluciones presentan un efecto diferencial respecto a la categoría base Escribir y hablar en idiomas extranjeros (para recibir una "remuneración económica arriba de los 5 mil pesos mensuales"). De igual forma, las competencias genéricas aplicadas Hacerse comprender, Participar y dirigir investigaciones y Redactar informes, documentos y publicarlos presentan un efecto diferencial respecto a la categoría base Escribir y hablar en idiomas extranjeros (para recibir una "remuneración económica arriba de los 5 mil pesos mensuales").

Las competencias genéricas aplicadas Dominio de su área o disciplina y Coordinar actividades presentan un efecto diferencial respecto a la categoría base Escribir y hablar en idiomas extranjeros (para conseguir un tipo de "contratación de base"). Así mismo, la competencia aplicada Encontrar nuevas soluciones presenta un efecto diferencial menor respecto a la categoría base Escribir y hablar en idiomas extranjeros (para conseguir un tipo de "contratación de base").

La competencia aplicada Encontrar nuevas soluciones presenta un efecto diferencial respecto a la categoría base Escribir y hablar en idiomas extranjeros (para insertarse en la "actividad académica").

Tales competencias genéricas aplicadas tienen relación con capacidades profesionalizantes, liderazgo, habilidades del pensamiento creativo, comunicativas y científicas. 
Todos estos resultados hablan de la importancia para el egresado de adquirir y aplicar competencias genéricas, y se confirma la necesidad de la formación por competencias para mejorar sus condiciones laborales.

En relación con el "sector productivo primario" y el "sector productivo secundario", presentan un efecto diferencial respecto a la categoría base "sector productivo terciario" (para que un egresado esté inserto en el "régimen jurídico público” y para dedicarse a la "actividad académica"). El "sector productivo primario" presenta un efecto diferencial respecto a la categoría base "sector productivo terciario" (para tener un tipo de "contratación permanente"). Y el "sector productivo $\mathrm{I}+\mathrm{D}+\mathrm{i}$ " presenta un efecto diferencial respecto a la categoría base "sector productivo terciario" (para tener una "remuneración económica arriba de los 5 mil pesos mensuales" y para tener una "actividad académica"). De esta forma, es posible afirmar que en estos modelos afectan más la pertenencia al "sector productivo primario" y al "sector productivo secundario" para que el egresado esté inserto en el "régimen jurídico público" y para dedicarse a la "actividad académica”, incluso aún más relevante que el área de conocimiento del posgrado o los años laborales del egresado.

También la "orientación del posgrado de investigación" presenta un efecto diferencial respecto a la categoría base "orientación del posgrado profesionalizante" (para conseguir un tipo de "contratación permanente").

Por otro lado, sobre el nivel de posgrado es posible decir que un egresado de "nivel especialización" presenta un efecto diferencial respecto a la categoría base "nivel maestría" (para que el egresado esté inserto en el "régimen jurídico público" y para insertarse en la "actividad académica"). Mientras que un egresado de "nivel doctorado" presenta un efecto diferencial respecto a la categoría base "nivel maestría” (para que el egresado esté inserto en el "régimen jurídico público", tenga una "contratación permanente" y para insertarse en la "actividad académica").

En cuanto a la variable "años laborales", un egresado con "más de cinco años laborales" presenta un efecto diferencial respecto a la categoría base "menos de cinco años laborales" (para que el egresado esté inserto en el "régimen jurídico público", tenga una "contratación permanente" y para insertarse en la "actividad académica").

También la variable "género masculino" presenta un efecto diferencial respecto a la categoría base "género femenino" (para que el egresado tenga una "remuneración económica arriba de los 5 mil pesos mensuales" y para que el egresado esté inserto en el "régimen jurídico público"). Y respecto al "área de conocimiento", el "área de conocimiento técnica” presenta un efecto diferencial menor respecto a la categoría base 
"área de conocimiento medicina y ciencias de la salud" (para que el egresado tenga un "tipo de contratación con base”). Además el "área de conocimiento de artes" presenta un efecto diferencial menor respecto a la categoría base "área de conocimiento ciencias de la salud" (para que el egresado esté inserto en el "régimen jurídico público"). Los porcentajes obtenidos son de acuerdo con los odd ratio respecto a la categoría base.

\section{Conclusiones}

El aporte al conocimiento sobre el análisis de los niveles de las competencias de egresados en relación con las características laborales, del perfil profesional y las características personales de los egresados, permite tres aplicaciones.

La primer aplicación está relacionada con el objetivo de analizar el nivel de competencias genéricas (divididas en la tipología utilizada como: técnicas, participativas, metodológicas, sociales y científicas de los egresados antes del posgrado) y compararlo con el nivel adquirido y aplicado en el ámbito laboral, y con la pregunta de investigación: ¿en qué medida los egresados adquieren y aplican competencias genéricas? Los niveles de competencias permiten a los programas educativos determinar la real aplicación del perfil de egreso, es decir, la aplicación de la formación por competencias desde el ámbito y actividad en la que se desempeña el egresado. En este sentido, se encontró que los programas educativos del posgrado de la uv pueden identificar que los egresados adquieren y aplican principalmente competencias relacionadas con profesionalización, habilidades del pensamiento analítico, de liderazgo y expositivas. Se concluye que, aunque un egresado como nivel inicial identifique poseer un nivel alto de competencias, es un hecho que durante su formación en el posgrado adquiere y fortalece sus competencias; es decir, el nivel de posgrado contribuye en su proceso formativo al desarrollo de competencias. Además es posible concluir que estos resultados permiten al nivel educativo de posgrado identificar la necesidad de fortalecer perfiles de egreso a partir de las competencias genéricas que los egresados adquieren en menor medida y que, sin embargo, sí aplican mucho. Estos resultados presentan los niveles de competencias genéricas iniciales, aplicadas y adquiridas de los egresados, sobre los cuales, en investigaciones como las del CONACYT (2008), han afirmado que los egresados pondrían en juego las competencias genéricas adquiridas en su trayectoria formativa, aun cuando el empleo no se encuentre en el área específica en la que se formaron. 
Por ejemplo, en la sociedad industrial se necesitaba de los profesionistas principalmente competencias técnicas para el sistema de producción en serie. Por su parte, la actual sociedad del conocimiento requiere de niveles de competencias adquiridas y aplicadas altas, enfocadas en el trabajo intelectual, en las que los egresados necesitan saber manejar y depurar grandes cantidades de información; para ello se requiere una tipología de competencias científicas, vinculadas con habilidades del pensamiento específicas.

Además es necesario decir que la importancia del estudio de las competencias genéricas a nivel de posgrado se debe a que los sistemas de posgrado deben tener una mayor incidencia en el impacto de la innovación y la productividad. Estudiar las competencias genéricas permite coadyuvar en el diseño curricular con parámetros armónicos entre la relación formativa universitaria en posgrado y el desarrollo social, económico, cultural, artístico, humano, tecnológico y científico, al determinar si los egresados en verdad adquieren las competencias genéricas, si éstas sirven para el mercado laboral, social y personal.

La segunda aplicación es referente al objetivo de analizar si las competencias genéricas de egreso han sido de utilidad para mejorar variables clave del mercado de trabajo, como son: el tipo de contratación, la actividad laboral, el régimen jurídico público y la remuneración económica; y la pregunta de investigación: ¿cuánto se relacionan las características del trabajo con la tipología de las competencias genéricas adquiridas y aplicadas? Se puede afirmar que las competencias genéricas aplicadas que mejoran las características del trabajo están relacionadas con las capacidades de liderazgo, comunicativas, científicas, profesionalizantes, habilidades del pensamiento crítico y creativo. Mientras que las competencias genéricas adquiridas que mejoran las características del trabajo están relacionadas con las capacidades científicas. Los niveles de competencias genéricas aplicadas y adquiridas en relación con las características del trabajo, identifican elementos de la pertinencia de los programas educativos, desde la formación integral por competencias, en la sociedad del conocimiento.

El análisis de las competencias genéricas en relación con las características del trabajo que consiguen los egresados permite al programa educativo identificar los requerimientos de competencias desde la sociedad; en este tiempo, desde la sociedad del conocimiento y la inversión del capital humano. La sociedad del conocimiento solicita que las personas posean una formación holística, un aprendizaje a lo largo de la vida, formación por competencias, que la formación permita a los egresados re- 
solver problemas y adaptarse a los cambios. Aunque la inserción laboral se puede ver influenciada por varios factores, como son la economía del país, la calidad de la formación universitaria y los requerimientos del mercado laboral. Los altos niveles de desempleo, incluso entre los más formados, hace importante profundizar en el análisis de las competencias que son demandadas y ofertadas en el mercado laboral, ya que de esto puede depender la inserción y satisfacción laboral de los graduados universitarios (Pineda, Ciraso \& Armijos, 2018).

La tercera aplicación es referente a la pregunta de investigación ¿cuánto se relacionan las características del trabajo con el perfil profesional, las características personales-laborales del egresado y las competencias genéricas? A partir del modelo logístico multinomial, se identificó que las variables que mejoran las características del trabajo están relacionadas con las competencias genéricas adquiridas vinculadas con las capacidades de habilidades de liderazgo, habilidades vinculadas con la actividad académica y científica. También con las competencias genéricas aplicadas relacionadas con capacidades profesionalizantes, liderazgo, habilidades del pensamiento creativo, comunicativas y científicas. Además, las variables relacionadas con: "sector productivo primario", "sector productivo secundario", "sector productivo $\mathrm{I}+\mathrm{D}+\mathrm{i}$ ”, "orientación de investigación", "nivel especialidad”, "nivel maestría”, años laborales ("más de cinco años laborales”), "género masculino”, “área de conocimiento técnica” y "área de conocimiento artes". De lo anterior, al nivel de posgrado le son de utilidad estos resultados para identificar la forma en la cual los perfiles profesionales influyen para que sus egresados consigan mejores características laborales. Además, para la institución y el programa educativo, este análisis de la relación de los perfiles profesionales y los perfiles de egreso con las características laborales, significa cubrir uno de los aspectos sugeridos para analizar en la evaluación del padrón de calidad del PNPC del CONACYT, desde la sugerencia: "el programa deberá contar con un sistema de seguimiento de egresados que permita medir el impacto del programa en el desempeño de sus egresados en los sectores de la sociedad afines a su formación" (CONACYT, 2016, p. 13).

El análisis de las características del trabajo con el perfil profesional, las características personales-laborales del egresado y las competencias genéricas coadyuva a que los programas educativos de posgrado identifiquen elementos sobre la pertinencia de los planes de estudio.

En este sentido, como lo han concluido las investigaciones de O'Connell y Russell (2008), Luchilo (2009) y Planas (2013), es posible determinar la calidad del em- 
pleo al medir las variables en relación con la formación previa y el tipo de contrato (permanente o temporal). En palabras de Bonilla (2015):

el desempeño laboral de los egresados del posgrado es uno de los indicadores más importantes de un programa, pues es la forma directa de verificar la pertinencia del programa, así como el desarrollo profesional de los graduados, el cual es el resultado de la formación dada a los estudiantes y de las habilidades que adquirieron. (p. 108)

También es posible afirmar que, en este caso, por medio de la valoración de la formación por competencias de egresados, algunas de las competencias identificadas con mayores grados de adquisición favorecen al egresado y lo colocan en ventaja para posicionarse en el mercado de trabajo.

El análisis de las características del trabajo con el perfil profesional, las características personales-laborales del egresado y las competencias genéricas permite a los programas educativos del posgrado conseguir evidencias, rasgos e indicadores para las evaluaciones y el aseguramiento de la calidad interna de la UV y del PNPC.

También es posible afirmar que la contribución del posgrado al desarrollo de competencias genéricas sí depende de variables como el perfil profesional y el perfil de egreso, tal y como lo identifican los resultados de esta investigación en el apartado sobre la relación de las características del trabajo con el perfil profesional, las características personales-laborales del egresado y las competencias genéricas, que analiza el efecto diferencial superior del perfil de egreso por competencias genéricas adquiridas y aplicadas, con las características personales-laborales del egresado y el perfil profesional (nivel de especialización, maestría y doctorado; orientación profesionalizante o de investigación, y por áreas de conocimiento).

Finalmente cabría resaltar que estos resultados permiten al posgrado conocer los niveles de competencias con los que llegan los egresados, aquéllos que necesitan adquirirse con base en los niveles requeridos en su desempeño laboral. También, el hecho de conocer las variables que mejoran las características del trabajo propicia el diseño de una oferta educativa con pertinencia social de programas educativos basada en los requerimientos de egresados y empleadores. Además, estos resultados presentan un panorama hasta hoy poco explorado, como lo es la articulación de la real adquisición de competencias en el nivel de posgrado, el perfil profesional, el perfil de egreso, las características personales-laborales del egresado y la política de desarrollo de la ciencia basada en el aprendizaje a lo largo de la vida. 
Los resultados de este artículo coadyuvarán a obtener reflexiones para en un futuro fortalecer los perfiles profesionales de planes de estudio, promoviendo actualizaciones y el diseño de nuevos planes de formación. Así, la línea de generación del conocimiento posterior será el análisis de las características del trabajo con el perfil profesional, las características personales-laborales del egresado y las competencias genéricas por áreas, niveles, orientaciones y planes de estudio del posgrado. Los datos sirven para dar elementos para valorar los planes de estudio que realmente funcionan, al medir la adquisición de lo aprendido por los egresados, desde los espacios laborales en los que aplican sus competencias. El aporte consiste en presentar un análisis sobre la relación de las competencias genéricas del posgrado con la inserción laboral.

\section{Lista de referencias}

Beneitone, P., Esquetini, C., González, J., Marty M., M., Siufi, G., \& Wagenaar, R. (Eds.). (2007). Reflexiones y perspectivas de la Educación Superior en América Latina, informe Final, proyecto tuning. América Latina, España y Países Bajos: Universidad de Deusto y Universidad de Groningen.

Beneyto, P. J. (2013). Teoría (y práctica) del capital humano. Un análisis crítico del cado español. Methaodos Revista de ciencias sociales, $1(1), 53-81$. doi: 10.17502/m. rcs.vii1.25

Blömeke, S., \& Kaiser, G. (Eds.). (2008). Professionelle Kompetenz angehender Lehrerinnen und Lehrer. Berlín: Waxmann.

Bonilla, M. (Coord.). (2015). Diagnóstico del posgrado en México: Nacional. Regiones Noroeste, Centro-Occidente, Centro-Sur, Metropolitana, Sur-Sureste. México: Consejo Mexicano de Estudios de Posgrado.

Bunk, G. (1994). La transmisión de las competencias en la formación y perfeccionamiento de profesionales de la ReFa. Revista Europea de Formación Profesional, 1, 8-14.

Carro, L., Lobato, M. L., Matas, J., \& Corchado, J. M. (Coords.). (2018). Diagnóstico sobre la empleabilidad de los egresados/as de las ramas de conocimiento de ciencias sociales, arte y humanidades de las universidades públicas de Castilla y León. España: Universidad de Burgos/Universidad de León/Universidad de Salamanca/Universidad de Valladolid.

Consejo Nacional de Ciencia y Tecnología. (2008). Evaluación de impacto del programa de formación de científicos y tecnólogos 1997-2006. México: Centro Redes. 
Consejo Nacional de Ciencia y Tecnología. (2016). Anexo A. Programa Nacional de Posgrados de Calidad. México: Autor/Secretaría de Educación Pública.

Corral, R. (2004). El currículum docente basado en competencias. Argentina: Consejo Latinoamericano de Ciencias Sociales.

Chatenier, E., Verstegen, J., Biemans, H., Mulder, M., \& Omta, O. (2010). Identification of competences for professionals in open innovation teams. R\&D Management, 40 (3). Recuperado de https://doi.org/10.1111/j.1467-9310.2010.00590.x

Dávila, C. D., Mora, J.-G., Pérez, P. J., \& Vila, L. E. (2015). ¿Es posible potenciar la capacidad de liderazgo en la universidad?. Innovar, 25(56), 129-140. doi:10.15446/ innovar.v25n56.48995

Dore, R. P. (1976). Human capital theory, the diversity of societies and the problem of quality in education. Research in Higher Education, 5, 79-102. doi:10.1007/ BFo1677208

Eizagirre, A., Altuna, J., \& Fernández, I. (2017). Prácticas de éxito en el desarrollo de competencias transversales en centros de formación profesional del País Vasco. Revista Española de Pedagogía, 75(267), 293-308. doi:10.22550/REP75-2-2017-7

Gilead, T. (2009). Human capital, education and the promotion of social cooperation: a philosophical critique. Research in Higher Education, 28, 555-578. doi:10.1007/ s11217-009-9146-2

Goffette, C., \& Vero, J. (2016). Desempleo y calidad del empleo de los jóvenes: una recorrida de Europa en crisis. Francia: Centro de Estudios e Investigaciones sobre Calificaciones.

Grediaga, R., Rodríguez, J. R., \& Padilla, L. E. (2004). Políticas públicas y cambios en la profesión académica en México en la última década. México: Asociación Nacional de Universidades e Instituciones de Educación Superior/Universidad Autónoma Metropolitana Azcapotzalco.

Grisales, Á. M., Carrión, A., \& Mora, J. (2015). El rol de los jóvenes profesionales universitarios en las organizaciones. Estudio comparativo Europa/Latinoamérica. Scientia Et Technica, 2o(2), 146-154.

Lozano A., L., Gandini, L. \& Ramírez G., T. (2015). Devaluación del trabajo de posgraduados en México y migración internacional: los profesionistas en ciencia y tecnología. Revista Migración y Desarrollo, 25, 61-89.

Luchilo, L. (2009). Los impactos del programa de becas del CONACYT mexicano: un análisis sobre la trayectoria ocupacional de los ex becarios 1997-2006. Revista Iberoamericana de Ciencia, Tecnología y Sociedad, 5(13), 175-205. 
Márquez, M. T. (1982). 10 años del Consejo Nacional de Ciencia y Tecnología. México: Consejo Nacional de Ciencia y Tecnología.

McClelland, D. (1973). Desarrollo de competencias directivas. Ajuste de la formación universitaria a la realidad empresarial. Boletín Económico ICE, 2795.

McDonald, B. (2018). Total VET program completion rates. Australia: National Centre for Vocational Education Research.

Méndez, T. J. (2018). La producción académica de los egresados del posgrado de instituciones de educación superior en México. Revista Educar, 54(2) 261-282. Recuperado de https://doi.org/10.5565/rev/educar.897

Migdelina, G. G. (2015). Estudiantes de posgrado: una muestra de perseverancia académica. Revista Iberoamericana de Ciencias, 1(1), 173-180.

Mora, J.-G., Carot, J. M., \& Conchado, A. (Eds.). (2010). El Profesional flexible en la sociedad del conocimiento. España: Universidad Politécnica de Valencia Centro de Estudios de la Calidad y el Cambio.

Moreno, M. G. (2013). Apoyo familiar, compromiso personal y disposición a las rupturas. Una historia de formación doctoral. En C. Barrón \& G. A. Valenzuela (Coords.), El posgrado programas y prácticas (pp. 133-173). México: Universidad Nacional Autónoma de México-Instituto de Investigaciones sobre la Universidad y la Educación.

O'Connell, P. J., \& Russell, H. (2008). Employment and the Quality of Work. En T. Fahey, Russell, H. and C.T., Whelan (Eds). Quality of Life in Ireland. Social Indicators Research Series. Dordrecht: Springer.

Organización para la Cooperación y el Desarrollo Económico. (2015a). Estudios económicos de la OCDE. México: Visión general/Autor. doi:10.1787/888933174843.

Organización para la Cooperación y el Desarrollo Económico. (2015b). Perspectivas económicas de América Latina 2015: Educación, competencias e innovación para el desarrollo, México: Centre de développement/Banco de desarrollo de América Latina/Naciones Unidas/Comisión Económica para América Latina y el Caribe de las Naciones Unidas.

Organización para la Cooperación y el Desarrollo Económico. (2017). Estudios económicos de la ocDE México.. Visión general. México: Autor.

Ojeda, M. M., \& Castro, C. R. (2013). Diagnóstico del Posgrado en el Estado de Veracruz. En M. Serna, J. M. Cabrera, R. M. Pérez \& M. Salinas (Eds.), Diagnóstico del posgrado en México: Ocho estudios de caso (pp. 261-308). México: Consejo Mexicano de Estudios de Posgrado.

Ojeda, M. M., Figueroa, S., Bernal, B., \& Castro, C. R. (Coords.). (2014). El primer es- 
tudio de egresados de posgrado en la Universidad Veracruzana. Xalapa, Veracruz, México: Imaginarial Editores.

Pineda, P., Ciraso, A., \& Armijos, M. (2018). Competencias para la empleabilidad de los titulados en Pedagogía, Psicología y Psicopedagogía: un estudio comparativo entre empleadores y titulados. Revista Española de Pedagogía, 76(270), 313-333. doi:10.22550/REP76-2-2018-06

Planas, J. (2013). Los itinerarios laborales de los universitarios y la calidad de su inserción profesional. Revista de la Educación Superior, 42(165), 31-62.

Rama, C. (2007). Los postgrados en América Latina y el Caribe en la sociedad del conocimiento. México: Unión de Universidades de América Latina y el Caribe.

Ramírez, V., \& Medina, G. (2008). Educación basada en competencias y el proyecto tuning en Europa y Latinoamérica. Revista Ideas, 39, 3-4.

Ruiz, G., \& Morfín, C. (Coords.). (2015). Diagnóstico del Posgrado en México. Región Centro-Occidente. Jalisco/Nayarit/Aguascalientes/Michoacán/Colima/Guanajuato. México: Consejo Mexicano de Posgrado.

Sánchez, M. D. (2014). Los programas de posgrado y becas del Conacyt y su impacto en el desarrollo de la ciencia y la tecnología en México. México: Gobierno de la República/Consejo Nacional de Ciencia y Tecnología.

Secretary's Commission on Achieving Necessary Skills. (200o). Informe de la comisión de la secretaría en el logro de nuevas competencias. Washington: Autor.

Serna, M., Cabrera, J. M., Pérez, R. M., \& Salinas, M. (2013). Diagnóstico del posgrado en México. Ocho estudios de caso. México: Consejo Mexicano de Posgrado.

Serna, M., \& Pérez, R. M. (Coords.). (2012). Logros e innovación en el Posgrado. México: Consejo Mexicano de Posgrado.

Schomburg, H., \& Teichler, U. (Eds.). (2006). Higher Education and Graduate Employment in Europe, Results of Graduate Surveys from Twelve Countries (Vol. 15, Serie: Higher Education Dynamics). Dordrech: Springer.

Van, J., \& Semeijn, J. (2004). Defining and Measuring Competences: An Application to Graduate Surveys. Research in Higher Education, 38, 331-349.

Villa, J. E. (2012). Comepo y el desarrollo del posgrado nacional. En M. Serna \& R. M. Pérez (Coords.), Logros e innovación en el Posgrado (pp. 11-14). México: Consejo Mexicano de Posgrado.

Villarreal, E. M. (2016). Externalidades del capital humano en México. El Trimestre económico, 83(332), 747-788. 